\title{
Analyses of the Existing Situation and Countermeasures of China's Children Sex Education - Taking Shanxi Province as an Example
}

\author{
Jiaqi Zhang \\ School of education, Tianjin Normal University, Tianjin, China,300387 \\ Corresponding author. Email: jiaqizhang0924@163.com
}

\begin{abstract}
In recent years, sexual abuse of young children has occurred frequently in China, and people's calling for children's sex education is increasing. At present, most of the research mainly focuses on the coastal economically developed areas, and the research on the central and western regions such as Shanxi Province is almost zero. To enrich this research field, this paper mainly studies the problems existing in early childhood education in Shanxi Province and puts forward some suggestions. Through questionnaires and interviews, three main problems were revealed: the acceptance of adult sex education does not match with practical action; kindergartens lack the carrier for early childhood sex education; and lack of communication and cooperation between teachers and parents. Therefore, the methods of popularizing sex education, setting up relevant courses and promoting home school cooperation need to be implemented. At the same time, early childhood sex education also needs the joint efforts of the whole society to be carried out reasonably and legally under the formulation of national policies.
\end{abstract}

Keywords: Sex education, children, parents, educational curriculum, school.

\section{INTRODUCTION}

According to the statistical data of the Investigation Report on Child Sexual Assault Cases and Child Sexual Assault Prevention Education released by the Girls Protection Fund of China Foundation of Culture and Art for Children, the total number of cases of sexual assault reported by the media in China in the past three years (2018-2020) is 317,301,332 respectively. Among 332 cases in 2020, the number of victims reached 845 , with an average of 2.55 children victims per case [1]. From the situation disclosed in the report, children's sexual safety in China is facing an extremely serious situation.

Due to the frequent exposure of child sexual assault cases, the research on child sex education has gradually increased in the past few years. On the platform of CNKI, the total number of papers on early childhood sex education increased year by year from 2018 to 2020, but decreased by nearly 200 in 2021. In addition, through retrieval, it is found that the current articles on children's sex education are mainly about the eastern or central regions with developed education, while Shanxi Province, one of the provinces in the central and western regions with relatively backward education development, has no articles on the issues related to children's sex education. Therefore, the purpose of this research is to find out and analyze the existing problems, and provide corresponding suggestions for kindergarten teachers and parents to effectively carry out preschool education of Shanxi Province in China.

Through questionnaire survey and interview, relevant data were collected and analyzed, and relevant problems and solutions of preschool sex education in Shanxi Province in kindergartens and parents were obtained, so as to help children in Shanxi better receive sex education and reduce the risk of sexual assault. At the same time, this study also provides references for the research on the current situation of children's sex education in China.

\section{A BRIEF INTRODUCTION OF CURRENT SITUATION OF CHILDREN'S SEX EDUCATION IN SHANXI PROVINCE}

\subsection{The definition of children sex education}

In terms of the content of sex education, the 
Sexuality Information and Education Council of the United States shows that sex education includes personal sexual knowledge, sexual ideas, sexual attitudes, sexual values and sexual behavior [2]. Ma Xiaonian, vice president of Beijing sex education research association, believes that sex education is a kind of health education. Learning knowledge is not only a simple education of sex knowledge, but also includes personality education, moral education and love education [3].

In terms of the subject and scope of sex education, sex education is an important part of family education, social education and school education. Formal sex education for children and adolescents needs the joint efforts of the whole society [4]. Similarly, You Kunting also holds the view that sex education is an important part of family education, school education and social education. Family and school are the main places to carry out early childhood sex education [5].

\subsection{The current situation of children sex education in Shanxi Province}

In recent years, there have been cases of sexual assault on children in Shanxi every year, such as the Houma case in 2018 and the Datong case in 2019. These cases show that Shanxi need to carry out appropriate sex education courses for children as soon as possible. When it comes to this topic, Guo Xiaoping, principal of Red Ribbon School in Linfen city, Shanxi Province, believes that sex education for children in Shanxi Province is extremely lacking. He also considers that sex education in Shanxi Province starts a little late and does not match the maturity of children today.

\section{METHODOLOGY}

\subsection{The questionnaire survey on the current situation of children's sex education in Shanxi Province}

This research mainly conducted a questionnaire survey on 139 kindergarten teachers and parents in Shanxi Province through the questionnaire star network platform. Among them, 55 are preschool teachers and 84 are preschool parents. At the same time, the choice of different age stages is also designed to test whether the questionnaire results can include the total population with a large age span.

A total of 25 questions were designed in the questionnaire, mainly including the attitude, cognition, implementation status and difficulties of adults (including teachers and parents) towards sex education. In addition, the content of this questionnaire has been analyzed for content validity.

\subsection{The interview on the current situation of children's sex education in Shanxi Province}

At the same time, to better understand the status and problems teachers face in carrying out early childhood sex education, this study interviewed teachers from different kindergartens in Shanxi Province, among whom 4 are female and 2 is male. The interview generally includes 10 main questions which are adjusted or communicated in depth according to the answers of the interviewees during the interview.

\section{RESULTS AND PROBLEMS}

According to the results of the questionnaire, there are three main problems in early childhood sex education in Shanxi Province: adults' awareness and action of sex education are seriously out of line; kindergartens lack the carrier for early childhood sex education; and lack of communication and cooperation between teachers and parents, which will be discussed in detail below.

\subsection{Adults' awareness and action of sex education are seriously out of line}

According to the results shown in figure 1, 64.23\% think it is very important to carry out sex education for young children, $27.01 \%$ think it is necessary, while only $8.76 \%$ think it is not so important. At the same time, $71.22 \%$ of respondents believe that students can receive sex education before primary school (including primary school).

Do you think it is important to develop sex education for young children?

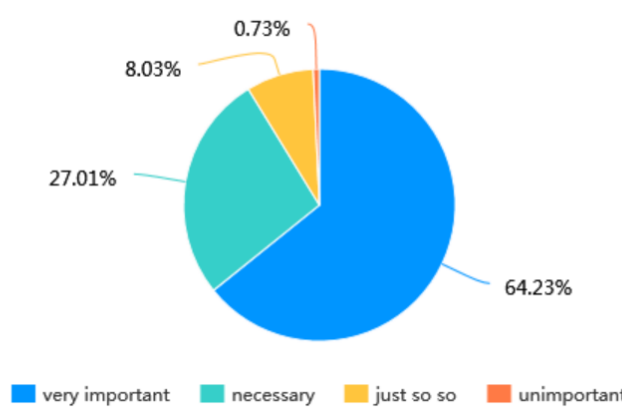

Figure 1 Questionnaire subjects' attitudes towards children's sex education

However, in the question "will you take the initiative to have sex education for young children", $62.04 \%$ of adults chose the option "No". This shows that adults in Shanxi Province have improved their acceptance of the children's sex education and are aware of the importance of the sex education, but they have not actively implemented it in practical action.

With the progress and development of The Times, people's ideas have been improved to some extent. In 
addition to the constant emergence of social problems catalytic effect, the importance of sex education gradually increased. Universal sex education has not only received attention from all walks of life, but also been welcomed by the masses. However, human sexology started late in China [6], and the influence of Chinese traditional culture and feudal thought for thousands of years is deeply rooted, which has always been a great resistance to the promotion of overall sex education in the mainland [7]. As a result, adults are deterred and difficult in the action of sex education.

\subsection{Kindergarten's lack of the carrier for early childhood sex education}

Most adults hope that schools can arrange relevant courses to carry out sex education for children (as shown in figure 2), accounting for up to $89.78 \%$, followed by family education which is chosen by $73.72 \%$ of people. Nevertheless, the questionnaire results showed that $62.5 \%$ of kindergartens in Shanxi Province did not offer sex education courses.

What way do you want to educate your child?

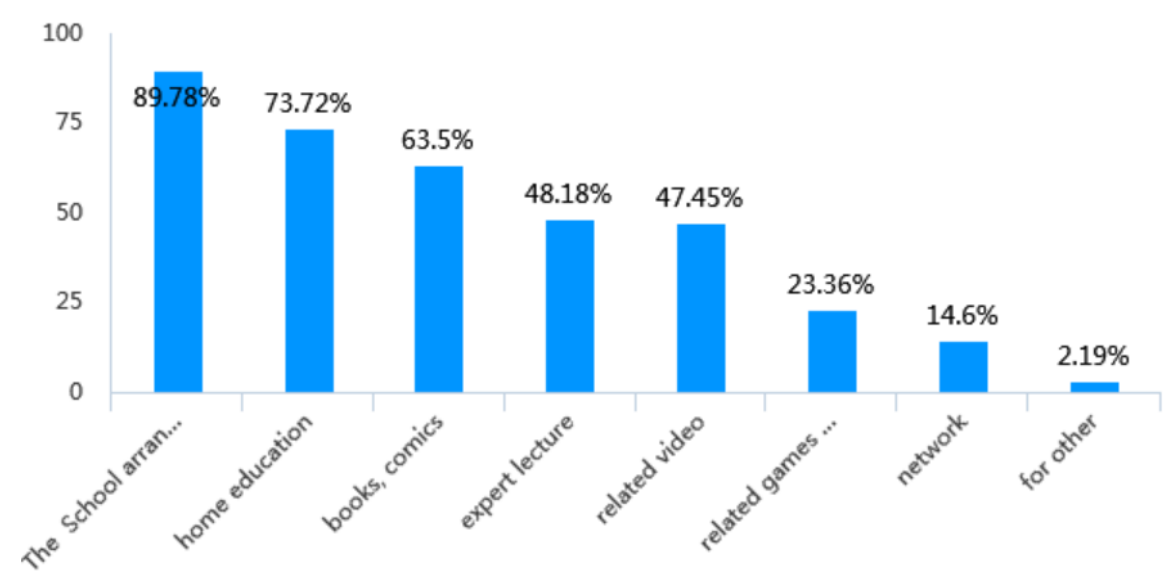

Figure 2 Questionnaire subjects' answers towards children's mode of sex education

What is more, in the interview, only one of the six teachers said that his kindergarten had ever carried out sex education for children. The six teachers interviewed said that there is no specific curriculum on children's sex education in kindergartens. The current documents guiding kindergartens in China, such as kindergarten working procedures and Learning and Development Guide for children aged 3-6, also only put forward a content directly related to sex education: "tell children not to allow others to touch their private parts". It could be seen that the attention is obviously not enough. In addition, the leaders of kindergarten, such as the head of the kindergarten and the teaching supervisor, will not actively involve the relevant contents of sex education in the kindergarten, nor will they develop the kindergarten based curriculum for children in combination with the actual situation of the kindergarten.

\subsection{Lack of communication and cooperation between teachers and parents}

Unlike other forms of education, sex education has the characteristics of personal privacy, which often makes adults don't know how to carry out it properly. In the questionnaire survey, nearly $67.88 \%$ of parents do not understand the methods of sex education for young children (shown in figure 3 ).
Do you think you know the way to sex educate young children?

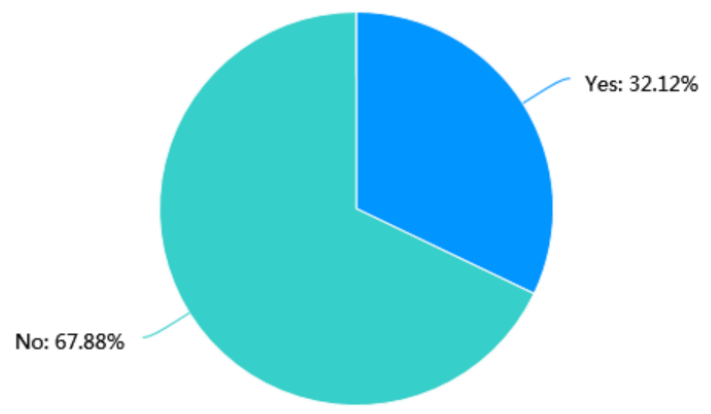

Figure 3 Questionnaire subjects' answers towards the way of educating

By contrast, through interviews with teachers, it is showed that most teachers have a general understanding of children's sexual and psychological development process and have preliminary knowledge of early childhood sex education during school or through their own learning. However, $60.38 \%$ of teachers will not mention the topic of early childhood sex education to parents on home school communication occasions such as parent meetings. They believe that parents will feel embarrassed or question the rationality of teachers' sex education ability. 


\section{SOLUTIONS}

\subsection{Popularize the commonly used methods of child sex education}

Educators and parents could choose suitable picture books to carry out sex education according to the age characteristics and physical and mental development of their children, avoiding disadvantages such as mechanical and blindness.

In the 21 st century, picture book reading has become a fashion for children all over the world. It is internationally recognized that: "picture books are the most suitable books for children to read [8]." In China, all the sex education books with a good reputation on the market are picture books [9]. Through vivid pictures and humorous words, sex education picture books can easily and naturally help educators and parents explain sex knowledge that they are unwilling to explain or do not know how to explain. At the same time, picture books also have the advantages of easy access, complete variety and selectivity. Currently, there are 134 picture books on sex education for children on sale in the domestic book market [10].

In addition to picture books, sex education can also be widely popularized through nursery rhymes. Reading picture books only allows children to complete the process of knowledge input of sex education, but nursery rhymes can enable children to internalize and output knowledge through verbal expression. For example, the Chinese nursery rhyme "Little Bear" tells children where is the private part and how to protect it, and it is easy to remember.

\subsection{Designing and implement child sex education curriculum}

Kindergartens should integrate the knowledge of sex education into children's regular courses, and make sex education a compulsory course in kindergartens. They could carry out sex education by combining children's role games, so that children can carry out gender role penetration education through children's social role imitation and play, and also let educators find appropriate opportunities to carry out and progress step by step in one-day life activities.

In addition, systematic sex education courses should also be studied and developed. For example, courses related to learning the names of sexual organs should be opened to let children gradually learn basic physiological knowledge; kindergartens could also set up self-protection courses to let children learn self-protection.

When formulating early childhood sex curriculum, kindergartens should actively develop school-based curriculum in line with local characteristics, but the most important thing is that the state should promulgate the outline of early childhood sex education curriculum so as to facilitate kindergartens to carry out relevant contents and grasp the scale of sex education. When formulating the curriculum, the government could properly refer to the foreign curriculum system, but it should adjust the corresponding curriculum objectives and contents according to the current situation of sex education in China.

\subsection{A good home-school cooperation}

Early childhood sex education is not just for families or kindergartens, both of them play an equally important role [11]. Kindergarten sex education needs parental approval, and parents also need professional guidance from teachers. Therefore, home-school cooperation and joint sex education are very important.

Parents should first establish a full relationship of trust with kindergarten teachers actively. Parents and teachers are a pair of cooperative partnership, and the premise of cooperation is trust. Parents should believe that kindergarten teachers can implement effective sex education for their children, and the sex knowledge taught by teachers is scientific. Teachers' guidance and requirements for parents are reasonable, and do not reject the normal sex education in kindergartens.

Secondly, kindergartens need to promote communication and exchange between parents and teachers through a variety of forms, such as parents' meeting, knowledge lectures, tutoring experience sharing meeting, parents' Open Day.

In addition, home-school communication should also attach importance to the use of the Internet. Online communication between parents and educators on childhood sex education can be carried out through Wechat, Tencent conference and other similar ways to realize home-school cooperation, complement each other's advantages and help children develop physically and mentally.

\section{DISCUSSION}

As a province in central and Western China, Shanxi Province can reflect the development of sex education in China to a certain extent. It can be seen that sex education has attracted more and more attention, and scientific and effective sex education has become the just need of today's society. However, as a large-scale system, sex education not only needs the attention and active participation of parents and teachers, but also needs the compulsion of national policies and the extensive cooperation of all sectors of society.

Government need to formulate or change policies from the following three aspects: 
The government can establishes an expert team in early childhood sex education and formulate national unified sex education curriculum and sex education teaching materials. At present, China is in the development period of early childhood education, and the knowledge and system of early childhood sex education will change constantly. Therefore, per-service and on-the-job training for teachers on child sex education should be appropriately increased to help teachers become more professional.

The admission system for teaching staff related to children should also be improved. The newly recruited teachers, administrative personnel, miscellaneous personnel, security personnel and other teaching staff working on campus in kindergartens should query the information about sexual assault and crimes before entering the job.

Looking ahead, the development of sex education in China still has a long way to go. Curriculum based school sex education is the main trend of future development, but sex education also needs to cooperate with parents and society to form a complete education system including school education, family counseling, extracurricular institutional training, one-to-one counseling and students' autonomous learning, so that children and parents can choose freely.

\section{CONCLUSION}

According to this study, the acceptance of sex education in Shanxi Province is good, but there are also some problems, such as the lack of practical development, the lack of relevant communications between educators and parents, and the shortage of scientific courses, which need the joint development of the state, families and kindergartens. Only when people from all walks of life continue to promote sex education, the quality of sex education in China could continue to improve gradually, and children could receive appropriate sex education and reduce the possibility of sexual assault. At the same time, this paper also has some deficiencies, such as most samples are from urban areas, only a few samples are from township areas, which can not cover the regional differences between urban and rural areas in Shanxi Province. In addition, the impact of adult education on sex education has not been shown in this study, which will become the direction of further research in the future.

\section{ACKNOWLEDGMENTS}

First of all, I would like to thank teacher Zhao for her supervision and encouragement in my thesis writing. I am also very grateful to the parents and teachers in Shanxi Province who are willing to participate in my research. Without your active participation and cooperation, this article can not be completed.

\section{REFERENCES}

[1] Baidu. "Girl Protection" released a survey report on child sexual assault prevention education. Retrieved November 19th, DOI:https://baijiahao.baidu.com/s?id=1693124262 $344610941 \& \mathrm{wfr}=$ spider \& for $=\mathrm{pc}$

[2] Debra W. Haffner (2004). From Diapers to Dating: Parents' guide to Raising Sexually Healthy Children [M]: Jieli Publishing House.

[3] Ma xiaonian. The role of fathers in sex education for boys [J]. Health Vision, 2; 2001, 51

[4] Guo Shaoling . Sex education of contemporary college students [J], China sex science, (10): (2005) 26-28

[5] By Kun ting (2014). Content selection and implementation plan of sex education in kindergartens $[\mathrm{J}]$. Science and education guide, (01)

[6] Zheng Zhiguo, LIU Jianping, ZHENG Qiao. Research Status and Prospects of school-age Children's sexual psychology [J]. Psychological exploration, 5 (2) : (2017) 111-116.

[7] li yan. The bottleneck and countermeasures of the development of child sex education $[\mathrm{J}]$. Education theory and practice, 28(33): (2008) 43-45

[8] Wang Quan-gen (2008). Children's Literature Course [M]. Beijing: Capital Normal University Press.

[9] Liu Yingzhu. Analysis of picture books on children's sexual knowledge education [J]. Art and technology, (3): (2017) 416

[10] Ma Ruijie, Zhang Cong. Thinking and wisdom about life: A Study on children's sex education picture books [J]. Publishing Science, (5): (2019) 45-51.

[11] Shtarkshall, R. A., Santelli, J. S., \& Hirsch, J. S..Sex education and sexual socialization: Roles for educators and parents. Perspectives on sexual and reproductive health, 39(2), (2007) 116-119. 